\title{
UM ESTUDO COMPARATIVO ENTRE A GESTÃO DA QUALIDADE TOTAL (TQM), O SEIS SIGMA E A ISO 9000
}

\section{A COMPARATIVE STUDY AMONG THE TOTAL QUALITY MANAGEMENT (TQM), THE SIX SIGMA AND ISO 9000}

\author{
Marcelo Giroto Rebelato ${ }^{1}$; Iraci Sobral de Oliveira ${ }^{2}$ \\ ${ }^{1}$ Pontifícia Universidade Católica do Paraná - PUCPR - Curitiba - Brasil \\ magiroto@pucpr.br \\ ${ }^{2}$ Pontifícia Universidade Católica do Paraná - PUCPR - Curitiba - Brasil \\ Iraci S Oliveira@bd.com
}

\begin{abstract}
Resumo
A competitividade é cada vez mais um fator de extrema importância para o sucesso das organizações, e a implantação de programas de qualidade pode ser um diferencial e uma vantagem competitiva na busca pela participação no mercado. Este artigo apresenta um estudo comparativo entre a Gestão da Qualidade Total (TQM), o Seis Sigma e a ISO 9000, realizado por meio de uma releitura dos seus respectivos conceitos, considerando as dimensões objetivo, foco, vantagens e desvantagens e barreiras para implantação. Busca-se analisar os pontos comuns e divergentes, assim como verificar a possibilidade de trabalhar estas iniciativas conjuntamente.
\end{abstract}

Palavras-chave: gestão da qualidade total; seis sigma; norma ISO 9000.

\section{Introdução}

Não é novidade o fato de que se vive numa sociedade em que a competição cresce a cada instante. As organizações buscam incessantemente maneiras de se tornarem mais competitivas. Uma dessas maneiras é a implementação de iniciativas, ferramentas e normas capazes de alavancar a qualidade de seus produtos ao menor custo possível.

Na busca pela excelência, surgem como solução para diminuir custo e melhorar a qualidade a implementação de iniciativas tais como: TQM (Total Quality Management ou Gestão da Qualidade Total), Seis Sigma e ISO 9000. A organização pode decidir por implementar o TQM, o Seis Sigma ou a ISO 9000 separadamente ou em conjunto, porém, seja qual for a decisão, o que se observa na prática é que a implementação de qualquer uma destas iniciativas é bastante trabalhosa para a empresa e um enorme desafio de coordenação para a organização. Há diversos requisitos e necessidades em termos de recursos materiais e humanos, e todo um árduo trabalho de 
conscientização para o comprometimento com o processo de implantação.

Decidir o que fazer, quando o assunto é implementar qualquer uma das três iniciativas é uma decisão difícil. O processo decisório não é um fim em si (MIRANDA, 1994). Ele só se completa depois que as idéias geradas tiverem sido avaliadas e uma solução tenha sido escolhida. O processo de avaliação das opções para escolha daquela ou daquelas iniciativas que serão efetivamente implementadas deve ser objetivo, imparcial e sereno. Para Pereira e Fonseca (1997), o processo decisório não se restringe à tomada de decisão, mas envolve todos os aspectos que antecedem e sucedem as decisões, a decisão é complexa porque seus efeitos se estendem por todos os sistemas sociais. Indivíduos e organizações estão profundamente inter-relacionados e um influencia o outro.

Este artigo tem por objetivo apresentar os conceitos de TQM, Seis Sigma e ISO 9000 e analisá-los comparativamente a partir de quatro dimensões: objetivo, foco, barreiras para a implantação e vantagens, desvantagens destas iniciativas. Trata-se de elementos-chave que devem ser conhecidos por qualquer organização que pretende implantar novos programas de gerenciamento. Além disso, avaliar-se-á se pode haver vantagens na utilização das iniciativas em conjunto.

\section{O TQM}

Para Berk (1997), o conceito de qualidade teve origem nos EUA, na década de 1920, e nesta época destinava-se apenas a limitar a produção de itens defeituosos. A partir dessa data, o conceito de qualidade sofreu inúmeros refinamentos, sendo que o trabalho pioneiro realizado por Shewhart, Deming, Juran, Feigenbaum, Crosby e outros, indicou a possibilidade de alternativas melhores de abordar a qualidade na fabricação. Uma filosofia administrativa mais eficiente poderia concentrarse em medidas para impedir que um produto deficiente fosse produzido. O TQM, no entanto, não prosperou nos EUA, mas a partir da $2^{\mathrm{a}}$ a Guerra, foi bem recebido no Japão. A qualidade superior se tornou tema comum do domínio do mercado japonês e os próprios japoneses contribuíram com o aprimoramento do TQM, mais notadamente nas áreas de redução da variabilidade, soluções de problemas, trabalho em equipe e identificação das expectativas do cliente.

De acordo com Oakland (1994), o TQM é uma abordagem para melhorar a competitividade, a eficácia e a flexibilidade da organização. É uma maneira de planejar, organizar e compreender cada atividade, e depende de cada individuo em cada nível. Para Samuel (1999), o TQM fornece um conceito geral que adota a melhoria contínua na organização. A filosofia TQM contém uma sistemática integrada, consistente na perspectiva da organização inteira, envolvendo todas as pessoas e todas as coisas. O TQM enfatiza o uso de todas as pessoas, geralmente em equipes multifuncionais. Segundo Zhu e Scheuermann (1999), o TQM foca externamente no atendimento aos requisitos do cliente, enquanto internamente no compromisso da gestão, treinamento e educação 
dos empregados. A participação dos empregados no programa TQM é uma necessidade para os processos de melhoria. Para Yusof \& Aspiwall (2000), o TQM tem sido descrito como uma iniciativa de gestão e uma maneira de pensar que tem ajudado muitas organizações a alcançar o status de classe mundial. Ele ajuda a criar uma cultura de confiança, participação, equipes de trabalho, zelo pela melhoria contínua, aprendizado contínuo, e por último uma cultura de trabalho que contribui para o sucesso e existência da empresa.

\subsection{Porque TQM falha?}

Zhu e Scheurmann (1999) enumeram algumas razões para a falha de TQM. São elas: individualismo; competitividade; orientação apenas para solução de problemas; orientação para controle, pensamento linear, falta de comprometimento da alta direção; falta de confiança dos empregados e obsessão por ganhar prêmios da Qualidade. Segundo Revere e Black (2003), uma das dificuldades no TQM é a medição. As equipes de TQM devem estabelecer critérios para avaliar os desvios, desenvolver meios para identificá-los e trabalhar para minimizá-los. De acordo com Oakland (1994), as medidas tradicionais de desempenho proporcionam pouco incentivo aos esforços de implantação de TQM porque são incompatíveis com medidas de aperfeiçoamento da qualidade. As medidas tradicionais (tais como: retorno sobre investimento e produtividade física) não têm sido vinculadas aos processos onde ocorrem as atividades de adição de valor. $\mathrm{O}$ que falta são medidas de melhoramento que forneçam feedback ao pessoal em todas as áreas da empresa.

Oakland (1994) observa que as lições básicas que as companhias mais bem sucedidas com o TQM têm aprendido podem ser resumidas da seguinte forma: o TQM é trabalho duro; implantar TQM demora mais do que se pensava inicialmente; o TQM precisa ser introduzido estrategicamente em toda a empresa; o comprometimento da alta e média gerências é vital; os campeões de TQM devem equilibrar seu entusiasmo com "praticabilidade"; os céticos nem sempre são um obstáculo, podem ser benéficos.

\section{O Seis Sigma}

Revere et al. (2004), afirmam que o Seis Sigma começou em 1980 como um plano da Empresa Motorola para melhoria da qualidade. Ele foi criado para acelerar a média de mudança no mercado competitivo por meio da redução de defeitos. A proposta tem, desde então, crescido e tem sido adotada por muitas companhias classe mundial. O Seis Sigma avalia a capacidade de o processo produzir livre de defeitos, dado que "defeito" é qualquer coisa que resulte em insatisfação do cliente. Pyzdek (2003) sustenta que o Seis Sigma se concentra na melhoria da qualidade ao ajudar as empresas a produzir de forma melhor, mais rápida e mais econômica. O Seis Sigma 
focaliza a prevenção de defeitos, a redução dos tempos de ciclo e a economia de custos. Sigma $\left(\sum\right)$ é uma letra do alfabeto grego utilizada pelos estatísticos para mensurar a variância em qualquer processo. O desempenho de uma empresa é medido pelo nível sigma de seus processos empresariais.

\subsection{Processo Seis Sigma}

Segundo Revelle (2004), o processo Seis Sigma acontece por meio da aplicação da iniciativa DMAIC: defyne, measure, analyze, improvement and control, ou seja, definir, medir, analisar, melhorar e controlar. $\mathrm{O}$ processo pode ser resumido em 12 passos divididos em cada uma das cinco fases DMAIC, conforme descrito na tabela 1.

Tabela 1 - Doze passos do processo Seis Sigma

\begin{tabular}{|c|c|}
\hline Fase & Passo \\
\hline Definir e Medir & $\begin{array}{l}\text { 1) selecionar produtos ou processos críticos para as } \\
\text { características de qualidade } \\
\text { 2) Definir o desempenho padrão } \\
\text { 3) Validar o sistema de medição } \\
\text { 4) estabelecer a capacidade do processo }\end{array}$ \\
\hline Analisar & $\begin{array}{l}\text { 5) Definir os objetivos de melhoria } \\
\text { 6) Identificar as fontes de variação } \\
\text { 7) Classificar causas potenciais para mudança e } \\
\text { identificar as únicas vitais }\end{array}$ \\
\hline Melhorar & $\begin{array}{l}\text { 8) Descobrir o relacionamento variável entre os poucos } \\
\text { vitais } \\
\text { 9) Estabelecer tolerâncias de operação nos poucos vitais } \\
\text { 10) Validar o sistema de medição para poucos vitais }\end{array}$ \\
\hline Controle & $\begin{array}{l}\text { 11) Determinar habilidade para controlar os poucos vitais } \\
\text { 12) Implementar o sistema controle de processo nos } \\
\text { poucos vitais }\end{array}$ \\
\hline
\end{tabular}

Fonte: Revelle (2004, p.42)

Para Pyzdek (2003), as empresas aceitam níveis de desempenho de 3 ou 4 sigma como normais, apesar de saberem que esses processos criam entre 6,2 mil e 67 mil problemas por milhão de oportunidades. O padrão seis sigma, de 3,4 problemas por milhão de oportunidades, é uma 
resposta ao aumento do nível de expectativas dos clientes e à crescente complexidade dos produtos e processos modernos. Conforme Eckes (2001), o conceito Seis Sigma baseia-se na teoria da variação. Todas as coisas que podem ser medidas com precisão são passíveis de variação, sendo que a maioria dos processos organizacionais que possam ser medidos em uma escala contínua segue a curva normal de variação. Esta curva representa quase 100\% daquilo que está sendo medido; é simétrica; o pico representa o valor de ocorrência mais freqüente ou a média; pode ser dividida em uma série de segmentos (desvio padrão), representado pela letra grega sigma. Cada segmento representa uma certa porcentagem daquilo que esta sendo medido. O preceito técnico do Seis Sigma é medir o desempenho atual e determinar quantos sigmas podem ser medidos a partir da média corrente até que ocorra a insatisfação do cliente (defeito). O sigma do processo representa o seu desempenho, isto é, a sua capacidade em atender às especificações. O nível de qualidade Seis Sigma representa um desempenho de 99,99966\% de conformidade ou 3,4 ppm de não conformidades.

Revelle (2004, p.42), explica porque 99,9\% bom não é bom o suficiente. Quando as coisas são reduzidas a números, tornam-se mais claras. Na prática $99,9 \%$ bom equivale ao seguinte:

- 18.000 perdas de artigos do correio a cada hora;

- 15 minutos a cada dia de água tomada insegura;

- 5.000 procedimentos cirúrgicos incorretos por semana;

- 2 ou mais acidentes por dia nos maiores aeroportos;

- 20.000 prescrições de medicamentos erradas a cada ano;

- 7 horas a cada mês sem eletricidade.

\section{A ISO 9000}

Segundo Drumond (1998), as normas da qualidade datam do início do século XX e foram adotadas pela primeira vez por indústrias de defesa na Grã-Bretanha e nos Estados Unidos. Seus objetivos iniciais eram fornecer produtos manufaturados de acordo com as especificações para facilitar o comércio internacional de produtos e reduzir custos de produção. A primeira versão da norma ISO 9000 foi lançada em 1987, com o objetivo de definir mundialmente um padrão para garantia da qualidade dos produtos das empresas. De acordo com Waks e Frank (1999), a ISO 9000 é um nome coletivo para uma série de normas internacionais para garantia da qualidade estabelecidos pelo International Standards Organization (ISO). As normas ISO 9000 não são de natureza técnica porque não especificam critérios ou regulam produtos e serviços. Ao invés disso requerem documentação particular nos procedimentos operacionais e ações gerenciais usadas para alcançar expectativas dos clientes.

As normas da série IS0 9000 surgiram como importante instrumento de referência para 
nivelamento dos sistemas produtivos de países integrantes de determinado bloco e também para regular o intercâmbio de mercadorias e serviços entre bloco econômico/bloco econômico, bloco econômico/país ou de país/país. Essas normas são acordos feitos entre duas partes (fornecedor e cliente) e possuem o papel fundamental de definir sob quais condições mínimas de gestão os produtos e serviços devem ser produzidos e comercializados, de maneira a se garantir sua padronização e, conseqüentemente, levar garantias de qualidade para os clientes. A nova versão da ISO 9000 (versão 2000) deu maior ênfase na melhoria continua e foco no cliente utilizando para tanto a ferramenta PDCA (Plan, Do, Check, Act, ou seja, planejar, fazer, checar e agir).

\section{Análise comparativa das iniciativas TQM, Seis Sigma e ISO 9000}

Para Waks e Frank (1999), a abordagem TQM e as normas ISO 9000 são inter-relacionadas. Uma organização que aplica a ISO 9000 em procedimentos básicos pode na próxima fase implantar a iniciativa TQM. Existem diferenças e semelhanças entre TQM e a ISO 9000. Primeiro, a ISO 9000 foca na consistência da produção de produtos/serviços por meio de um sistema "auditável” e “certificável”. O TQM, apesar de ter este foco, não define necessariamente um sistema e não garante a certificação. Segundo, obter a certificação ISO 9000 é uma boa maneira de medir o progresso da empresa. O mesmo pode ser conseguido também com o TQM. Este, porém, pode ter melhores impactos na produtividade, na manutenção dos equipamentos e na motivação dos funcionários.

O Seis Sigma contêm diretrizes muito próximas às do TQM. Porém, devido à grande necessidade da utilização de ferramentas estatísticas, o Seis Sigma pode se tornar excessivamente caro, as economias obtidas podem ser menores do que o custo para alcançar melhorias. Por outro lado, o Seis Sigma e a ISO 9000 limitam a responsabilidade a poucas pessoas da organização, enquanto que o TQM envolve todos os empregados. Entretanto, nem a certificação ISO 9000, nem o TQM, nem tampouco o Seis Sigma garantem a qualidade do produto.

De acordo com Harry, (2003) o TQM não apresentou o resultado esperado mundialmente porque, entre outras dificuldades, faltou-lhe um objetivo específico. O Seis Sigma, ao contrário, tem sua meta muito concreta, que é registrar menos de 3,4 erros por milhão de oportunidades de errar, em produtos e serviços. Já Pyzdek (2003), afirma que 80\% das implementações de TQM fracassaram por não proporcionarem uma infra-estrutura para garantir que as atividades de melhoria de desempenho obtivessem os recursos necessários.

As iniciativas TQM, ISO 9000, e Seis Sigma têm como ponto em comum a melhoria contínua. Porém, o foco de cada iniciativa é diferente: o TQM tem foco mais interno no compromisso da gestão, na mudança cultural e treinamento e educação do empregado, e 
externamente no atendimento dos requisitos dos clientes. A ISO 9000 enfoca a gestão por processos e na satisfação dos clientes. O Seis Sigma enfoca a redução das variações dos processos organizacionais, estimulando a realização de ajustes nestes se os resultados não são satisfatórios.

$\mathrm{Na}$ tabela 2 são apresentados os dados comparativos das dimensões: objetivo, foco e barreiras para implantação. Na tabela 3 são apresentadas as vantagens e desvantagens de cada uma das iniciativas.

Tabela 2 - Comparativo entre TQM, Seis Sigma e ISO 9000

\begin{tabular}{|c|c|c|}
\hline TQM & Seis Sigma & ISO 9000 \\
\hline Objetivo: Melhoria contínua. & $\begin{array}{l}\text { Objetivo: Reduzir a variabilidade dos } \\
\text { processos. }\end{array}$ & $\begin{array}{l}\text { Objetivo: satisfazer as necessidades } \\
\text { dos clientes. }\end{array}$ \\
\hline $\begin{array}{l}\text { Foco: Satisfação do cliente interno e } \\
\text { externo, compromisso da gestão, } \\
\text { treinamento e educação do } \\
\text { empregado. }\end{array}$ & $\begin{array}{l}\text { Foco: na prevenção de defeitos, na } \\
\text { redução dos tempos de ciclo e na } \\
\text { economia de custos. }\end{array}$ & $\begin{array}{l}\text { Foco: na gestão por processo e na } \\
\text { satisfação dos clientes }\end{array}$ \\
\hline $\begin{array}{l}\text { Barreiras para Implantação: } \\
\text { Falta de envolvimento e } \\
\text { comprometimento da direção; } \\
\text { Mudança cultural; } \\
\text { Entendimento muito limitado da } \\
\text { qualidade; } \\
\text { Outros interesses que não de } \\
\text { qualidade; } \\
\text { Políticas organizacionais; } \\
\text { Cinismo; } \\
\text { Estrutura organizacional; } \\
\text { Falta de treinamento e educação dos } \\
\text { emprega; }\end{array}$ & $\begin{array}{l}\text { Barreiras para Implantação: } \\
\text { Falta de envolvimento e } \\
\text { comprometimento da direção; } \\
\text { Mudança cultural; } \\
\text { Infra-estrutura da organização; } \\
\text { Treinamento; habilidades de } \\
\text { gerenciamento de projeto, priorização } \\
\text { e seleção de projetos, análise e } \\
\text { rastreabilidade; } \\
\text { Compreensão da iniciativa Seis } \\
\text { Sigma, ferramentas e técnicas; } \\
\text { Integração entre Seis Sigma e a } \\
\text { estratégia de negócios; Integração } \\
\text { entre Seis Sigma e cliente; } \\
\text { Integração Seis Sigma e recursos } \\
\text { humanos; } \\
\text { Integração Seis Sigma e } \\
\text { fornecedores.; } \\
\text { Custo e tempo gasto na implantação; } \\
\text { Considerar o método como uma série } \\
\text { de projetos, pois é um grave erro } \\
\text { entender o Seis Sigma como um } \\
\text { projeto. }\end{array}$ & $\begin{array}{l}\text { Barreiras para implantação: } \\
\text { Falta de envolvimento e } \\
\text { comprometimento da direção; } \\
\text { Excesso de burocracia; } \\
\text { Falta de habilidade para entender a } \\
\text { aplicação dos fatores que afetam a } \\
\text { seleção da parte apropriada; } \\
\text { Dificuldade de interpretação de várias } \\
\text { seções da norma como os requisitos } \\
\text { de calibração e a extensão de } \\
\text { documentos necessários.; } \\
\text { Medo de mudar para iniciar o projeto. }\end{array}$ \\
\hline
\end{tabular}

Fonte: os autores 
Tabela 3 - Vantagens e desvantagens na utilização do TQM, Seis Sigma e ISO 9000

\begin{tabular}{|c|c|c|c|c|c|}
\hline \multicolumn{2}{|c|}{ TQM } & \multicolumn{2}{|c|}{ Seis Sigma } & \multicolumn{2}{|c|}{ ISO 9000} \\
\hline Vantagens & Desvantagens & Vantagens & Desvantagens & Vantagens & Desvantagens \\
\hline $\begin{array}{l}\text { Torna a } \\
\text { organização mais } \\
\text { competitiva e } \\
\text { viável; } \\
\text { Impulsionando } \\
\text { mudança e } \\
\text { melhoria; } \\
\text { Pode } \\
\text { proporcionar } \\
\text { lucratividade, } \\
\text { redução de } \\
\text { custos, } \\
\text { criatividade e } \\
\text { inovação, } \\
\text { accountability e } \\
\text { um ambiente de } \\
\text { trabalho mais } \\
\text { agradável ; } \\
\text { Melhora a } \\
\text { sinergia } \\
\text { organizacional; } \\
\text { Remove } \\
\text { atividades não } \\
\text { produtivas; } \\
\text { Maior confiança } \\
\text { no sistema de } \\
\text { comunicação. } \\
\text { Aumento no } \\
\text { lucro; } \\
\text { Aumento da } \\
\text { participação no } \\
\text { mercado; } \\
\text { Aumento de } \\
\text { produtividade; } \\
\text { Redução de } \\
\text { defeitos; } \\
\text { Redução do } \\
\text { alcançaro a ara } \\
\text { quadade. } \\
\text { a }\end{array}$ & $\begin{array}{l}\text { Não possui } \\
\text { critérios de } \\
\text { medição; } \\
\text { Não possui uma } \\
\text { meta clara, } \\
\text { demora em } \\
\text { atingir o } \\
\text { resultado } \\
\text { esperado; } \\
\text { Necessita grande } \\
\text { mudança } \\
\text { cultural. } \\
\text { Necessita } \\
\text { desenvolvimento } \\
\text { de todos os } \\
\text { empregados da } \\
\text { organização }\end{array}$ & $\begin{array}{l}\text { Melhoria na } \\
\text { satisfação do } \\
\text { empregado; } \\
\text { Redução do } \\
\text { tempo de ciclo e } \\
\text { variação; } \\
\text { Melhoria na } \\
\text { segurança do } \\
\text { local de trabalho } \\
\text { e saúde; } \\
\text { Medição da } \\
\text { acuracidade e } \\
\text { Constância; } \\
\text { Melhoria } \\
\text { contínua do } \\
\text { processo; } \\
\text { Melhoria da } \\
\text { capabilidade de } \\
\text { processo e } \\
\text { rendimentos; } \\
\text { Defesa em } \\
\text { competição; } \\
\text { Ganho de } \\
\text { mercado; } \\
\text { Melhoria dos } \\
\text { resultados } \\
\text { operacionais; } \\
\text { Retorno de } \\
\text { investimentos; } \\
\text { Redução de custo } \\
\text { o produto. }\end{array}$ & $\begin{array}{l}\text { Necessidade de } \\
\text { grande } \\
\text { conhecimento de } \\
\text { estatística, } \\
\text { Uso de } \\
\text { ferramentas } \\
\text { complexas, alto } \\
\text { custo de } \\
\text { implantação; } \\
\text { Limitado a } \\
\text { poucas pessoas; } \\
\text { Não promove a } \\
\text { integração das } \\
\text { pessoas na } \\
\text { organização. }\end{array}$ & 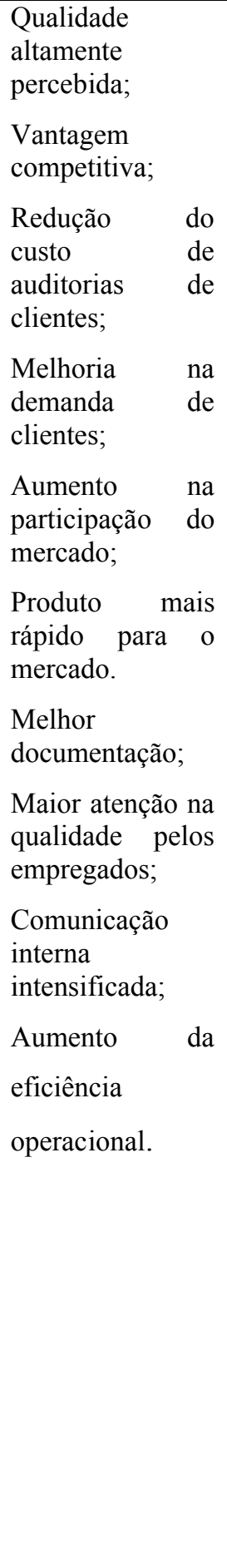 & $\begin{array}{l}\text { Excesso de } \\
\text { burocracia; } \\
\text { Limita a } \\
\text { responsabilidade } \\
\text { pela qualidade á } \\
\text { pequenos grupos } \\
\text { dentro da } \\
\text { organização }\end{array}$ \\
\hline
\end{tabular}

Fonte: os autores

Uma pesquisa realizada por Antony e Banuelas (2002) com empresas mundiais apresentou o seguinte resultado: $71 \%$ das companhias implementaram ISO 9000 e TQM e apenas 14\% não apresentaram nenhum programa de qualidade. Mais que 50\% das companhias têm iniciativas Seis Sigma e estão trabalhando com três ou mais níveis de sigma. A pesquisa também revela que $31 \%$ 
das empresas pesquisadas trabalham com as iniciativas TQM, Seis Sigma e ISO 9000 conjuntamente. Cada iniciativa possui vantagens e desvantagens. Assim, uma pode compensar a outra. Nenhuma das iniciativas prejudica a implantação da outra, elas sempre se complementam em um processo de fortalecimento.

\section{Conclusões}

O TQM, o Seis Sigma e a ISO 9000, têm como maior e imprescindível requisito o total comprometimento da alta administração. Sem este, quaisquer das três iniciativas pode resultar num alto nível de desgaste da organização e não alcançar os resultados esperados.

O TQM e o Seis Sigma podem ser implementados em conjunto, pois utilizam as mesmas técnicas e ferramentas estatísticas. Já para empresas que já possuem TQM, trabalhar com o Seis Sigma fica muito mais fácil por já haver uma cultura de qualidade. A ISO 9000 pode também ser implementada em conjunto com o TQM e o Seis Sigma, pois tem o papel principal de documentar e padronizar as atividades. Porém, pode-se dizer que o ideal seria iniciar todo o processo de alavancagem da qualidade com ISO 9000 e, somente depois dos processos documentados e padronizados, seguir-se para as outras iniciativas.

O TQM, o Seis Sigma e a ISO 9000 se aproximam, pois usam ferramentas semelhantes, envolvem os empregados, buscam a melhoria contínua dos processos e dependem do envolvimento da alta direção para ter sucesso. Apesar de não serem idênticos em termos de objetivos, foco, vantagens e desvantagens, também não são conflitantes. Dessa forma é perfeitamente possível trabalhar com eles conjuntamente, aproveitando as características que são semelhantes e utilizando as características diferentes para reforçar as lacunas existentes.

Cada uma das iniciativas estudadas tem seu potencial e pode ajudar a organização a se tornar mais competitiva e nenhuma pode substituir a outra já que elas apresentam características e objetivos diferentes.

Seja para qualquer das iniciativas, um programa de treinamento e conscientização será necessário, muito embora para o Seis Sigma a literatura ressalte uma maior necessidade de preparação, devido ao amplo uso de ferramentas estatísticas.

Independentemente da iniciativa a ser aplicada, é necessário que haja dedicação, comprometimento de toda organização, participação da alta gerência, treinamento, trabalho em equipe, para que a organização seja bem sucedida no processo de implantação de qualquer uma das iniciativas isoladas ou em conjunto.

$\mathrm{Na}$ profundidade em que foi estudado o artigo permitiu visualizar um comparativo das dimensões escolhidas e também comprovar a possibilidade de trabalhar com as iniciativas em 
conjunto, uma vez que estas possuem muitos pontos em comum, sendo que a diferenciação de foco e pode ser uma vantagem no sucesso da implantação. O assunto também pode ser desenvolvido de modo prático em trabalhos futuros, na implantação de iniciativas para melhoria da qualidade.

\begin{abstract}
The competitiveness is becoming more and more a factor of extreme importance for the success of the organizations, and the implantation of quality programs can be a differential and a competitive advantage in the search for the participation in the market. This paper presents a comparative study among the Total Quality Management (TQM), the Six Sigma and the ISO 9000, carried through by means of a re-analysis of its respective concepts, considering the dimensions objective, focus, advantages and disadvantages and barriers for implantation. It searchs to analyze the common and divergent points, as well as verifying the possibility to work these initiatives jointly.
\end{abstract}

Key-words: Total Quality Management, Six Sigma, ISO 9000.

\title{
Referências
}

ANTONY, J.; BANUELAS R. () Key Ingredients for the effective implementation of Seis Sigma program. Measuring Business Excellence, v.6, n.4, pp. 20-27, 2002.

cross ${ }^{\text {ref }}$

BERK, J. Administração da qualidade total. São Paulo: IBRASA, 1997.

DRUMOND, H. Movimento pela qualidade: de que o gerenciamento de qualidade total realmente trata. São Paulo: Littera Mundi., 1998.

ECKES, G. A revolução seis sigma: o método que levou a GE e outras empresas a transformar processos em lucros. Rio de Janeiro: Campus, 2001.

HARRY, M. Conselhos do padrinho. HSM Management, Maio-junho, p. 78-81, 2003.

MIRANDA, R.L. Qualidade total: rompendo as barreiras entre a teoria e a prática. São Paulo: Makron Books do Brasil Editora Ltda., 1994.

OAKLAND, J. Gerenciamento da qualidade total. São Paulo: Nobel, 1994.

PEREIRA, M.L.B.; FONSECA, J.G.M. Faces da decisão: as mudanças de paradigmas e o poder da decisão. São Paulo: Makron Books, 1997.

PYZDEK, T. Uma Ferramenta em busca do defeito Zero. HSM Management, Maio-junho. p.64-70, 2003.

REVELle, J. B. Six Sigma: Problem-solving techniques create safer, healthier worksites, Professional Safety, October, p. 39-46, 2004.

REVERE, L.; BLACL, K.; HUQ, A. Integrating seis sigma and CQI for improving patient care. The TQM Magazine, volume 16- number 2, p. 105-113, 2004.

REVERE, L.; BLACL, K. Integrating six sigma with total quality management: a case example for measuring medication errors. Journal of Healthcare Management, 48:6 November/ December, p. 377-391, 2003.

SAMUEL, K.M.O. Change for the better via ISO 9000 and TQM. Management Decision, vol.37, n.4, p.381-385, 1999.

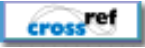


WAKS, S.; FRANK M. Application of the total Quality management approach principles and the ISO 9000 standards in engineering education. European Journal of Engineering Education, vol.24, n. 3, p.249-258, 1999.

cross ${ }^{\text {ref }}$

YUSOF, M.S.; ASPIWALL E. Total quality management implementation frameworks: comparison and review, Total Quality Management, vol.11, n.3, p.281-294, 2000.

cross ${ }^{\text {ref }}$

ZHU, Z;. SCHEUERMANN L. A comparison of quality programmes: Total quality management and ISO 9000. Total Quality Management, vol.10, Nº.2, p.291-297, 1999.

cross ${ }^{\text {ref }}$

\section{Dados do autor:}

Nome completo: Marcelo Giroto Rebelato

Filiação institucional: Professor: Programa de Pós-Graduação em Engenharia de Produção e

Sistemas (PPGEPS) - PUCPR

Endereço completo para correspondência (bairro, cidade, estado, país e CEP):

Rua Benedito Antunes de Oliveira - 179

CEP: 81570-320 - Curitiba - PR

Telefones para contato: PUC: (41) 32711332

e-mail: m.giroto@pucpr.br

Recebido para publicação em: 13/11/2005

Aceito para publicação em: 23/02/2006 